\title{
EVALUASI PENERAPAN MANAJEMEN CARA PEMBENIHAN \\ IKAN YANG BAIK (CPIB) PADA UNIT PEMBENIHAN \\ UDANG DINAS KELAUTAN DAN PERIKANAN PROVINSI SULAWESI SELATAN DI BOJO KABUPATEN BARRU
}

\section{(Evaluation of the Implementation of Goodanagement of Fishethry Unit of the Incedepartmen of Marine and Fisheries in Bojo, Barru Regency, South Sulawesi Province)}

\author{
Hartati $^{1)}$ Jayadi $^{2)}$ dan Andi Tamsil ${ }^{2)}$ \\ 1) Dinas Kelautan dan Perikanan Sulawesi Selatan \\ 2) Program Studi Budidaya Perairan FPIK UMI Makassar
}

Korespondensi:hartatiaziz19@gmail.com

Diterima: 22 Agustus 2019; disetujui 22 Oktober 2019

\begin{abstract}
Evaluation of the implementation of good management of fish hatchery (CPIB) at the shrimp hatchery unit of the Departmen of marine and fishery in south Sulawesi province in Bojo, Barru regensy. This research was conducted in February 2019 until April 2019 at the shrimp hatchery until of the Departmen of Marine and Fisheries in south Sulawesi in Bojo, Barru regency. The hatchery unit is a barometer of other shrimp hatcheries in Barru regency in particular and those in South Sulawesi province in general. Based on the results of research using the analysis method ( $t$ test) and linear regression shows that the implementation of good management of fish hatchery (CPIB) has an excellent effect on shrimp seed production and internal management factors that affect almost $70 \%$ of successful seed production are water quality management, master management, feed management, larvae management and personnel management and the remaining around $30 \%$ of production is influenced by external factors such as environment and others. To increase the production of shrimp seed in hatchery units, is it necessary to seek for adjustments and performance enhancements and still be giuded by the method of good hatchery (CPIB) in implementing the 5 production management steps as internal factors greatly determine the success level of seed production both in quantity and quality.
\end{abstract}

Keyword : Shrimp hatchery, regulation, implementation, managemen CPIB

\begin{abstract}
ABSTRAK
Evaluasi Penerapan Manajemen Cara Pembenihan Ikan yang Baik (CPIB) Pada Unit Pembenihan Udang Dinas Kelautan dan Perikanan Provinsi Sulawesi Selatan Di Bojo Kabupaten Barru. Penelitian ini bertujuan mengidentifikasi masalah dan faktor-faktor yang berpengaruh terhadap penerapan manajemen CPIB dalam produksi benih. Penelitian ini dilaksanakan pada bulan Februari 2019 sampai tanggal bulan April 2019 di unit pembenihan udang Dinas Kelautan dan Perikanan Provinsi Sulawesi Selatan di Bojo Kabupaten Barru. Unit pembenihan tersebut merupakan barometer terhadap pembenihan udang lainnya yang ada di Kabupaten Barru pada khususnya dan yang ada Diprovinsi Sulawesi Selatan pada umumnya. Berdasarkan hasil penelitian dengan menggunakan metode analisis (uji t) dan Regresi Linear menunjukkan bahwa penerapan manajemen cara Pembenihan Ikan yang Baik (CPIB) berpengaruh sangat baik terhadap produksi benih udang dan faktor-faktor internal manajemen yang mempengaruhi hampir $70 \%$ keberhasilan produiksi benih adalah manajemen kualitas air, manajemen induk, manajemen pakan, manajemen larva dan manajemen personil dan selebihnya sekitar $30 \%$ produksi dipengaruhi oleh faktor luar yaitu lingkungan dan lainnya. Dalam usaha meningkatkan produksi benih udang pada unit pembenihan maka perlu dilakukan upaya perbaikan dan peningkatan kinerja dan tetap berpedoman pada Cara Pembenihan Ikan yang Baik (CPIB) dalam melakukan penerapan dari ke 5 unsur manajemen produksi tersebut sebagai faktor internal yang sangat menentukan tingkat keberhasilan produksi benih baik secara kuantitas maupun kualitas.
\end{abstract}

Kata kunci : Pembenihan udang, regulasi, penerapan, manajemen CPIB. 


\section{PENDAHULUAN}

Menghadapi perkembangan
perekonomian dunia khususnya
perdagangan bebas maka masalah standarisasi, sertifikasi dan akreditasi merupakan pedoman penting sebagai jaminan kepercayaan bagi produk yang diperdagangkan. Sektor perikanan Indonesia memiliki beberapa komoditas unggulan yang bernilai ekspor, salah satunya adalah udang yang telah mencapai pasar internasional. Udang adalah salah satu komuditas unggulan sektor perikanan Indonesia karena ekspornya meningkatkan devisa negara.

Pembenihan ikan merupakan suatu mata rantai paling utama sebagai penunjang kelangsungan proses budidaya perikanan. Keberhasilan budidaya perikanan tidak terlepas dari ketersediaan bibit yang baik dari segi kualitas maupun kuantitas secara berkesinambungan. Benih yang bermutu dicirikan antara lain: pertumbuhan cepat, seragam, sintasan tinggi, adaptif terhadap lingkungan pembesaran, bebas parasit dan tahan terhadap penyakit. Agar dihasilkan benih yang bermutu dan layak edar, maka dalam kegiatan usaha pembenihan harus menerapkan tehnik sesuai dengan standar dan prosedur yang baik. Cara Perbenihan Ikan yang Baik (CPIB) merupakan sistem manajemen mutu perbenihan dalam rangka menghasilkan benih bermutu yang memenuhi persyaratan keamanan pangan dan ramah lingkungan (BSN, 2014). Penerapan Cara Perbenihan Ikan yang Baik (CPIB) sebagai suatu standar yang berlaku nasional, maka perlu dilakukan pembinaan kepada pelaku usaha perbenihan untuk menghasilkan benih yang lolos mutu, (DKP Sul-Sel 2015). Dengan diterbitkannya Peraturan Menteri Kelautan dan Perikanan Republik Indonesia Nomor 35/PERMENKP/2016 Tentang Cara Perbenihan Ikan yang Baik (CPIB) dengan pertimbangan bahwa dalam rangka pengendalian mutu induk dan benih ikan, keamanan pangan, kesehatan dan kenyamanan ikan, serta tanggungjawab terhadap lingkungan. Berdasarkan latar belakang diatas, maka perlu dilakukan penelitian Evaluasi Penerapan Manajemen Cara Pembenihan Ikan yang Baik (CPIB) sesuai Peraturan Nomor 35/PERMENKP/2016 Tentang Cara Pembenihan Ikan yang Baik (CPIB). Tujuan penelitian ini (1) Mengindentifikasi 
masalah dengan cara mengevaluasi penerapan manajemen CPIB pada produksi benur di unit pembenihan udang Dinas Kelautan dan Perikanan di Bojo Kabupaten Barru Provinsi Sulawesi Selatan. (2) Melihat faktor faktor yang berpengaruh terhadap penerapan manajemen CPIB di unit pembenihan udang Dinas Kelautan dan Perikanan di Bojo Kabupaten Barru, Provinsi Sulawesi Selatan.

\section{METODE PENELITIAN}

Penelitian dilaksanakan di unit pembenihan udang dinas kelautan dan perikanan di Bojo Kabupaten Barru, Provinsi Sulawesi Selatan pada bulan Pebruari sampai dengan bulan April 2019. Data penelitian meliputi data primer dan sekunder. Data primer diperoleh dengan melalui wawancara dan koesioner oleh teknisi utama dari pembenihan yaitu teknisi bagian kualitas air, teknisi bagian induk, teknisi bagian pakan dan tehnisi bagian larva sedangkan data sekunder yang merupakan data penunjang di dapatkan dari unit pembenihan setempat berupa laporan produksi, instansi terkait, study pustaka, peraturan menteri serta dokumen lain yang berkaitan dengan penelitian ini.
Teknik analisa data yang akan di gunakan dalam penelitian ini adalah (1) Analisis (Uji T) dengan software SPSS, untuk mengidentifikasi masalah sebelum dan sesudah penerapan manajemen CPIB pada produksi benih udang di unit pembenihan udang dengan menggunakan data laporan produksi sebelum penerapan CPIB yaitu selama 3 tahun, dan setelah penerapan CPIB yaitu selama 3 tahun. Statistik Deskriktif atau Uji t merupakan bagian dari analisis data yang memberikan gambaran awal setiap variabel yang digunakan dalam penelitian, gambaran atau deskriptif suatu data tersebut dapat dilhat dari nilai rata rata (mean), maksimum, minimum, dan standar deviasi dari setiap variabel yang digunakan dalam penelitian ini (Ghozali, 2005).

Analisis Regresi Linier adalah metode statistika yang digunakan membentuk model hubungan antara variabel terikat/dependen (Y) dengan satu atau lebih variabel bebas/independen (X), (https://idstatistik.com, 2013).

Analisis regresi linier dalam penelitian ini digunakan untuk menganalisis faktor- faktor (variabel indenpenden) yang berpengaruh yaitu : manajemen kualitas air, manajemen 
induk, manajemen pakan, manajemen larva dan manajemen personil (X) pada penerapan manajemen CPIB sesuai standar persyaratan CPIB pada produksi benur (Y) (variabel dependen) di unit pembenihan. Dengan persamaan regresi linier berganda sebagai berikut :

$$
\mathrm{Y}=\mathrm{a}+\mathrm{bX} 1+\mathrm{cX} 2+\mathrm{dX} 3+\mathrm{eX} 4+\mathrm{fX} 5
$$

Keterangan :

$\mathrm{Y}=$ produksi (variabel dependen)

$\mathrm{X} 1=$ manajemen kualitas air (variabel independen)

$\mathrm{X} 2=$ manajemen induk (variabel independen)

$\mathrm{X} 3$ = manajemen pakan (variabel independen)

$\mathrm{X} 4=$ manajemen larva (variabel independen)

$\mathrm{X} 5=$ manajemen personil (variabel independen)

a $\quad$ konstanta (nilai $\mathrm{Y}$ apabila $\mathrm{X} 1, \mathrm{X} 2 \ldots . . \mathrm{X} 5=0$ )

$$
\mathrm{b}, \mathrm{c}, \mathrm{d}, \ldots . \mathrm{f}=\text { koefisien }
$$
regresi (nilai peningkatan atau penurunan)

Tingkatan data secara berturut dari skala terendah ke tertinggi adalah data nominal, ordinal, interval dan ratio. Dalam penggunaan analisis, umumnya ditentukan skala minimal dari data yang dibutuhkan. Namun sering kali data yang kita miliki tidak memenuhi persyaratan tersebut. Misalnya, data ordinal, sementara persyaratan alat analisis membutuhkan data dengan skala minimal adalah data interval. Dalam kondisi tersebut, perlu dilakukan pentransformasian data dari skala ordinal ke interval (Junaidi, 2014). Metode transformasi data yang digunakan yakni method of successive interval, Hays (1976). Metode tersebut digunakan untuk melakukan transformasi data ordinal menjadi data interval. Pada umumnya jawaban responden yang diukur dengan menggunakan skala likert (Lykert scala) diadakan scoring yakni pemberian nilai numerikal 1,2,3,4, dan 5 setiap skor yang diperoleh akan memiliki tingkatan pengukuran ordinal.

\section{HASIL DAN PEMBAHASAN}

\section{Analisis Uji t}

Menurut Lasima et al. (2012). bahwa mutu benih merupakan salah satu faktor penentu keberhasilan usaha budidaya udang, sehingga dalam kegiatan usahanya harus menerapkan teknik pembenihan sesuai Standar Nasional Indonesia (SNI) dan Standar Operasional Prosedur (SOP), serta 
menerapkan manajemen mutu 35/PERMEN-KP/2016 Tentang Cara perbenihan, yaitu Cara Pembenihan Pembenihan Ikan yang Baik (CPIB). Ikan Yang Baik (CPIB) atau Good Pengolahan data yang di Uji t dalam Hatchery Practices (GHP). penelitian ini adalah hasil dari jumlah

Kajian dalam penelitian ini produksi benur sebelum dilakukan adalah evaluasi penerapan manajemen penerapan manajemen CPIB dan Cara Pembenihan Ikan yang Baik setelah penerapannya, yaitu masing(CPIB) sesuai dengan peraturan masing 3 (tiga) tahun dan pertahunnya Menteri Kelautan dan Perikanan sebanyak 2 siklus produksi. Republik Indonesia Nomor

Tabel 1. Data produksi benih 3 Tahun sebelum dan 3 Tahun sesudah penerapan CBIB

\begin{tabular}{ccccc}
\hline No & Siklus & Tahun & Sebelum & Sesudah \\
\hline $\mathbf{1}$ & I & 2013 & 1.750 .000 & \\
& II & & 1.350 .000 & \\
$\mathbf{2}$ & I & 2014 & 1.000 .000 & \\
& II & & 1.000 .000 & \\
$\mathbf{3}$ & I & 2015 & 1.200 .000 & \\
& II & & 2.101 .000 & \\
$\mathbf{4}$ & I & 2016 & & 1.527 .000 \\
& II & & & 1.534 .000 \\
$\mathbf{5}$ & I & 2017 & & 1.723 .000 \\
& II & & & 2.000 .000 \\
$\mathbf{6}$ & I & 2018 & & 3.127 .000 \\
\hline
\end{tabular}

Hal ini dapat terlihat dari data hasil produksi bibit udang pada Tabel 1 dari tahun 2013 sampai tahun 2015 adalah sebelum dilakukan penerapan manajemen Cara Pembenihan Ikan yang Baik (CPIB) dan data produksi setelah dilakukan penerapan manajemen Cara Perbenihan Ikan yang Baik (CPIB) dari tahun 2016 sampai 2018 terlihat adanya peningkatan jumlah produksi benih yang di hasilkan pada pembenihan tersebut. 
Tabel 2. Hasil analisis Uji t

\begin{tabular}{|c|c|c|c|c|c|c|c|c|c|}
\hline & & \multicolumn{5}{|c|}{ Paired Samples Test } & \multirow{5}{*}{$\mathrm{t}$} & \multirow[b]{2}{*}{ d } & \multirow{5}{*}{$\begin{array}{c}\text { Sig. } \\
(2- \\
\text { tailed) }\end{array}$} \\
\hline & & \multirow{4}{*}{ Mean } & \multicolumn{4}{|c|}{ Paired Differences } & & & \\
\hline & & & \multirow{3}{*}{$\begin{array}{c}\text { Std. } \\
\text { Deviation }\end{array}$} & \multirow{3}{*}{$\begin{array}{l}\text { Std. Error } \\
\text { Mean }\end{array}$} & \multirow{2}{*}{\multicolumn{2}{|c|}{$\begin{array}{l}95 \% \text { Confidence Interval } \\
\text { of the Difference }\end{array}$}} & & $\mathrm{f}$ & \\
\hline & & & & & & & & & \\
\hline & & & & & Lower & Upper & & & \\
\hline \multirow{3}{*}{$\begin{array}{l}\text { Pai } \\
\text { r } 1\end{array}$} & sebelum & - & 477470.4 & 194926.4 & - & - & - & 5 & .035 \\
\hline & - & 560000.0 & 18 & 82 & 1061074.4 & 58925.52 & 2.87 & & \\
\hline & Sesudah & 00 & & & 74 & 6 & 3 & & \\
\hline
\end{tabular}

Berdasarkan hasil analisis Uji t pada Tabel 2, produksi benih sebelum dan sesudah dilakukan penerapan manajemen CPIB diperoleh hasil signifikan, yaitu sebesar 0,035 dan ini artinya ada perbedaan hasil jumlah produksi benur sebelum dilakukan penerapan CPIB dan setelah dilakukan penerapan CPIB, dimana setelah dilakukan penerapan manajemen CPIB pada pembenihan tersebut mengalami adanya peningkatan produksi dan berpengaruh positif terhadap produksi benih. Hal ini diduga, bahwa dengan adanya pedoman penerapan manajemen Cara Pembenihan Ikan yang Baik (CPIB) dalam berbagai kegiatan teknis produksi dan lingkungan pembenihan menyebabkan adanya kemudahan dalam melaksanakan berbagai kegiatan teknis produksi, adanya kesadaran, serta disiplin kerja bagi personil untuk meningkatkan produksi benih yang bermutu dan memiliki daya saing produk benih yang dihasilkan.

\section{Analisis Regresi Linier Berganda}

Hasil rekapitulasi menunjukkan data koesioner dan wawancara yang lengkap dari setiap sub bidang tehnis manajemen produksi sebagai faktor independen (mempengaruhi) terhadap produksi benur sebagai faktor dependen (yang dipengaruhi) di unit pembenihan udang yang keseluruhannya berjumlah 20 orang, yaitu : pelaksana manajemen kualitas air, manajemen induk, manajemen pakan, manajemen larva dan manajemen personil.

Keberhasilan produksi benih pada pembenihan udang baik skala besar, menengah maupun skala kecil atau skala rumah tangga sangat dipengaruhi oleh berbagai faktor baik internal maupun faktor eksternal. Faktor internal yang paling berpengaruh terhadap produksi benih 
dalam lingkup kerja pada pembenihan adalah beberapa elemen manajemen produksi seperti manajemen kualitas air, manajemen induk, manajemen pakan, manajemen larva, dan manajemen personil sedangkan faktor eksternal yang berpengaruh terhadap produksi adalah lingkungan dan konsumen.

Pengolahan data secara analisis Regresi Linear berganda dalam Tabel 3. Data kualitatif (Ordinal) penelitian ini dilakukan dengan menggunakan data Kualitatif (Ordinal) yang diubah menjadi data Kuantitatif (Interval) dengan cara transpormasi data ordinal ke interval dengan microsoft office excel agar dapat dilakukan analisis Regresi Linear berganda dengan metode yang digunakan dapat dilihat pada Tabel 3 dan 4.

\begin{tabular}{cccccc}
\hline $\mathbf{Y}$ & $\mathbf{X 1}$ & $\mathbf{X 2}$ & $\mathbf{X 3}$ & $\mathbf{X 4}$ & $\mathbf{X 5}$ \\
\hline $\mathbf{5}$ & 5 & 2 & 4 & 4 & 5 \\
$\mathbf{2}$ & 5 & 3 & 3 & 4 & 5 \\
$\mathbf{3}$ & 5 & 2 & 4 & 5 & 5 \\
$\mathbf{4}$ & 4 & 2 & 3 & 4 & 4 \\
$\mathbf{2}$ & 5 & 5 & 5 & 3 & 5 \\
$\mathbf{3}$ & 4 & 3 & 4 & 4 & 4 \\
$\mathbf{3}$ & 4 & 3 & 2 & 2 & 4 \\
$\mathbf{3}$ & 4 & 2 & 4 & 4 & 4 \\
$\mathbf{2}$ & 3 & 2 & 4 & 4 & 3 \\
$\mathbf{2}$ & 4 & 2 & 4 & 4 & 4 \\
$\mathbf{3}$ & 4 & 3 & 1 & 1 & 2 \\
$\mathbf{1}$ & 1 & 1 & 3 & 3 & 1 \\
$\mathbf{3}$ & 4 & 4 & 4 & 4 & 4 \\
$\mathbf{3}$ & 4 & 2 & 4 & 4 & 4 \\
$\mathbf{2}$ & 4 & 3 & 5 & 5 & 4 \\
$\mathbf{2}$ & 4 & 3 & 4 & 4 & 4 \\
$\mathbf{2}$ & 2 & 2 & 5 & 5 & 3 \\
$\mathbf{2}$ & 4 & 2 & 4 & 4 & 4 \\
$\mathbf{2}$ & 3 & 3 & 4 & 4 & 4 \\
$\mathbf{2}$ & 4 & 2 & 4 & 4 & 4 \\
\hline
\end{tabular}


Tabel 4. Data kuantitatif (Interval)

\begin{tabular}{cccccc}
\hline $\mathbf{Y}$ & $\mathbf{X 1}$ & $\mathbf{X 2}$ & $\mathbf{X 3}$ & $\mathbf{X 4}$ & $\mathbf{X 5}$ \\
\hline $\mathbf{4 , 8 2}$ & 4,46 & 2,48 & 3,20 & 3,13 & 4,46 \\
$\mathbf{4 , 8 2}$ & 4,46 & 3,69 & 2,11 & 3,13 & 4,46 \\
$\mathbf{3 , 5 4}$ & 4,46 & 2,48 & 3,20 & 4,62 & 4,46 \\
$\mathbf{4 , 2 2}$ & 3,06 & 2,48 & 2,11 & 3,13 & 3,06 \\
$\mathbf{2 , 4 1}$ & 4,46 & 5,13 & 4,62 & 2,02 & 4,46 \\
$\mathbf{3 , 5 4}$ & 3,06 & 3,69 & 3,20 & 3,13 & 3,06 \\
$\mathbf{3 , 5 4}$ & 3,06 & 3,69 & 1,62 & 1,62 & 3,06 \\
$\mathbf{3 , 5 4}$ & 3,06 & 2,48 & 3,20 & 3,13 & 3,06 \\
$\mathbf{2 , 4 1}$ & 2,02 & 2,48 & 3,20 & 3,13 & 2,02 \\
$\mathbf{2 , 4 1}$ & 3,06 & 2,48 & 3,20 & 3,13 & 3,06 \\
$\mathbf{3 , 5 4}$ & 3,06 & 3,69 & 1,00 & 1,00 & 1,62 \\
$\mathbf{1 , 0 0}$ & 1,00 & 1,00 & 2,11 & 2,02 & 1,00 \\
$\mathbf{3 , 5 4}$ & 3,06 & 4,51 & 3,20 & 3,13 & 3,06 \\
$\mathbf{3 , 5 4}$ & 3,06 & 2,48 & 3,20 & 3,13 & 3,06 \\
$\mathbf{2 , 4 1}$ & 3,06 & 3,69 & 4,62 & 4,62 & 3,06 \\
$\mathbf{2 , 4 1}$ & 3,06 & 3,69 & 3,20 & 3,13 & 3,06 \\
$\mathbf{2 , 4 1}$ & 1,62 & 2,48 & 4,62 & 4,62 & 2,02 \\
$\mathbf{2 , 4 1}$ & 3,06 & 2,48 & 3,20 & 3,13 & 3,06 \\
$\mathbf{2 , 4 1}$ & 2,02 & 3,69 & 3,20 & 3,13 & 3,06 \\
$\mathbf{2 , 4 1}$ & 3,06 & 2,48 & 3,20 & 3,13 & 3,06 \\
\hline
\end{tabular}

Tabel 5. Hasil Analisis Regresi Faktor-faktor yang mempengaruhi Produksi

\section{Coefficients $^{a}$}

\begin{tabular}{|c|r|r|r|r|r|r|r|}
\hline \multirow{2}{*}{ Model } & \multicolumn{2}{|c|}{$\begin{array}{c}\text { Unstandardized } \\
\text { Coefficients }\end{array}$} & $\begin{array}{c}\text { Standardized } \\
\text { Coefficients }\end{array}$ & \multirow{2}{*}{$\mathrm{t}$} & \multicolumn{2}{c|}{ Sig. } & \multicolumn{2}{c|}{ Collinearity Statistics } \\
\cline { 2 - 4 } & \multicolumn{1}{|c|}{ B } & Std. Error & \multicolumn{1}{c|}{ Beta } & & & Tolerance & VIF \\
\hline (Constant) & 1.414 & .844 & & 1.675 & .116 & & \\
X1 & .487 & .425 & .474 & 1.146 & .271 & .138 & 7.267 \\
X2 & .155 & .198 & .153 & .781 & .448 & .614 & 1.628 \\
X3 & -.715 & .239 & -.702 & -2.993 & .010 & .429 & 2.331 \\
X4 & .454 & .252 & .435 & 1.801 & .093 & .403 & 2.481 \\
X5 & .159 & .442 & .155 & .360 & .724 & .127 & 7.857 \\
\hline
\end{tabular}

Hasil dari data kualitatif koefisien yang menyatakan hubungan (Ordinal) menjadi kuantitaf (Interval) antar variabel independent (yang yang dilakukan analisis regresi linear menunjukkan persamaan sebagai berikut:

$$
\begin{aligned}
& Y=1,414+0,487\left(X_{1}\right)+0,155\left(X_{2}\right)- \\
& 0,715\left(X_{3}\right)+0,454\left(X_{4}\right)+0,159\left(X_{5}\right)+e
\end{aligned}
$$

mempengaruhi) yaitu $\mathrm{X}_{1}, \mathrm{X}_{2}, \mathrm{X}_{3}, \mathrm{X}_{4}, \mathrm{X}_{5}$ terhadap variabel dependent $\mathrm{Y}$ (yang dipengaruhi). Persamaan tersebut dapat diartikan bahwa peningkatan kinerja manajemen kualitas air, 
manajemen induk, manajemen larva dan manajemen personil berpengaruh positif terhadap produksi kecuali dengan peningkatan kinerja manajemen pakan dan menyebabkan produksi benur dapat turun. Hal ini diakibatkan bahwa dalam manajemen pakan mengukur dan mengestimasi kebutuhan pakan alami dan pakan buatan sangat sulit dilakukan disebabkan oleh pakan alami yang dapat berkembang dengan sendirinya didalam bak larva sehingga terjadi bloming yang dapat mengakibatkan persaingan kebutuhan oksigen dan ruang gerak antara larva dan algae. Sedangkan menurut Djunaedi et al. (2016) bahwa kualitas air cenderung semakin jelek sebanding dengan lamanya waktu pemeliharaan karena terjadi kenaikan input pakan dan pertambahan berat benih selanjutnya akan meningkatkan konsentrasi bahan organik dan faeses didalam media pemeliharaan. Hal ini akan meningkatkan pelepasan senyawasenyawa yang bersifat toksit dan membahayakan benih yang dipelihara, seperti amoniak dan nitrit.

\section{KESIMPULAN}

Hasil analisis uji $t$ terhadap produksi benur menunjukkan adanya perbedaan yang signifikan 0,035 dimana terjadi peningkatan produksi setelah penerapan manajemen CPIB walau belum sepenuhnya dilakukan apa yang disarankan dalam pedoman CPIB. Sedangkan hasil analisis regresi linier berganda menunjukkan adanya pengaruh faktor-faktor independen (manajemen kualitas air, manajemen induk, manajemen pakan, manajemen larva dan manajemen personil) terhadap dependen (produksi) dengan nilai koefisien sebesar $70 \%$ dan $30 \%$ dipengaruhi oleh faktor lain.

\section{SARAN}

Faktor-faktor manajemen CPIB lainnya yang berpengaruh terhadap produksi hendaknya dapat dilaksanakan secara optimal, perlu perhatian khusus dari pihak pengelola tentang bagaimana cara agar CPIB dapat terlaksana dengan baik.

\section{UCAPAN TERIMA KASIH}

Tulisan ini merupakan bagian dari hasil penelitian tesis dan penulis mengucapkan terima kasih kepada Dinas Kelautan dan Perikanan Provinsi Sulawesi Selatan yang telah memberi izin untuk melanjutkan studi. 


\section{DAFTAR PUSTAKA}

[BSN]. Badan Standarisasi Nasional, 2014, Cara Perbenihan Ikan yang Baik, Jakarta (ID); BSN.

Dinas Kelautan dan Perikanan Provinsi Sulawesi Selatan, 2015. Pedoman Umum Cara Pembenihan Ikan yang Baik, Makassar.

Djunaedi A., Susilo H., Sumaryo., Jurnal Kelautan Tropis 2016. Kualitas Air Media Pemeliharaan Benih Udang Windu (Panaeus Monodon Febricius) dengan Sistem Budidaya yang Berbeda, Departemen Kelautan Fakultas Perikanan dan Ilmu Kelautan, UNDIP.

Ghozali I.,2005. Aplikasi Analisis Multivariate dengan Program SPSS. Badan Penelitian Universitas Diponegoro, Semarang.

Hays, W. L. 1976. Quantification In Psychology. Prentice Hall. New Delhi. https;/idstatistik.com.2013.

Publication Papers.

Junaidi, 2014. Transformasi Data Ordinal ke Interval dengan Microsof Office Excel Fakultas Ekonomi dan Bisnis Universitas Jambi: Seri Tutorial Analisis Kuantitatif, 2014.

Kementerian Kelautan dan Perikanan. 2016. Peraturan Menteri Kelautan dan Perikanan Nomor :35/PERMEN-KP/2016. Tentang Cara Pembenihan Ikan yang Baik (CPIB).

Lasima, W., Syamsun, M., Kadarisman, D., Jurnal Tingkat Penerapan Mutu pada UMKM pada Pembenihan Udang di Jawa Timur 2012. Kementrian Kelautan Perikanan, Departemen Manajemen Fakultas Ekonomi Manajemen Intitut Pertanian Bogor, Departemen Ilmu dan Tehnologi Pangan Fakultas Tehnologi Pertanian Bogor.

(https://idstatistik.com, 2013). 